\title{
A arte ao alcance da criança e o desenho de Amador Perez
}

\author{
Ludmila Vargas Almendrai
}

\section{Resumo}

Os desenhos de Amador Perez reinterpretam imagens extraídas da cultura visual e artística, convidando-nos a encarar a visualidade como experiência, espécie de iniciação e abertura ao mundo percebido. Quais as motivações da dedicação ao desenho e do interesse pelo redesenho de imagens recolhidas do mundo, sobretudo do mundo da arte, na poética desse artista? Nosso objetivo, nesse artigo, é refletir acerca de experiências na infância de Amador Perez, que parecem repercutir na produção profissional. Através do enfoque fenomenológico, examinamos as exigências da visualidade diante das imagens e na experiência do desenho. Presentes no processo criativo do artista maduro, as experiência da criança podem inspirar outras percepções sobre a frequentação das imagens.

Palavras-chave: experiência, visualidade, fenomenologia, Amador Perez.

\section{Abstract}

Amador Perez drawings reinterprets images extracted from the artistic and visual culture, inviting us to regard the visuality as experience, sort of initiation and opening to the perceived world. What are the motivations to the dedication to the drawing and to the interest in the redrawing of images collected from the world, especially the world of art, in the artist's poetic? The article presents a reflection upon experiences in Amador Perez childhood, which seems to resonate in his professional production. Through phenomenology, we examined the demanding of visuality by the images and the drawing experience. Present in the creative process of the mature artist, the child's experience may inspire others perceptions about the frequentation of images.

Keywords: experience, visuality, phenomenology, Amador Perez.

\section{Uma introdução}

Amador Perez (1952) é um artista que desenha. No final dos anos de $1970^{1}$, início da vida profissional, Perez já sinalizava a escolha do desenho como meio de expressão. Ainda que, ao longo da carreira, que completou quarenta anos em 2014, venha se dedicando também a outras técnicas, o desenho, entendido aqui mais como processo do que como produto, anima sua poética, como uma espécie de princípio, um impulso desenhante. A singularidade do trabalho de Amador se traduz na precisão com que indica o desenho como chave de sua experiência artística, exercendo-o de modo próprio e elevado ao mais alto grau de excelência técnica, ao mesmo tempo em que o atualiza, como expressão artística contemporânea. Motivado pela "oportunidade para problemas perpértuos e precisos" oferecidos pelo desenho (VALÉRY, 2003, p.121), esse artista se vê constantemente convocado à tarefa de interrogar 0 território que 0 desenho circunscreve, os aspectos da criação que ele revela pelo traçar, os limites do traçado

${ }^{1}$ Informações sobre fortuna crítica e biografia do artista podem ser encontradas no site oficial: http://www.amadorperez.com 
como potência expressiva, sua capacidade de representar e de se apresentar. Ao atender a esse apelo, o artista não pode fazê-lo a não ser pelo exercício, perseguindo e atualizando permanentemente os fundamentos do desenho, reinventando os modos de tematizar o traçado. É preciso que, pela invenção, construam-se os modos de seu aparecer e que o desenho traga consigo um mundo dado a visualização: o mundo de Perez, e também o mundo do desenho e o da arte, revisitados pelo artista, que desenha a partir de imagens pré-existentes (ALMENDRA, 2013).

Os desenhos de Amador Perez reinterpretam imagens extraídas da cultura visual e artística, convidando-nos a encarar a visualidade como experiência, espécie de iniciação e abertura ao mundo percebido. Quais as motivações da dedicação ao desenho e do interesse pelo redesenho de imagens recolhidas do mundo, sobretudo do mundo da arte, na poética desse artista? Nosso objetivo, nesse artigo, é refletir acerca de experiências na infância de Amador Perez, que parecem repercutir na produção profissional. Através do enfoque fenomenológico, examinamos as exigências da visualidade e o exercício do olhar, diante das imagens e na experiência do desenho. Presentes no processo criativo do artista maduro, as experiência da criança podem inspirar outras percepções sobre a frequentação das imagens.

\section{Desenho: uma experiência ancorada no mundo percebido}

O significado do desenho mostra-se variável e impreciso, principalmente no território da visualidade e da arte. Derdyk (2007), Chuí e Tiburi (2010) destacam a natureza abrangente e transdisciplinar do desenho, ao mesmo tempo fundadora e instituinte do fato artístico. Discorrer sobre significados ou definições de desenho, sua trajetória na história da arte ou características enquanto técnica não é nosso propósito. Ao adotar o enfoque fenomenológico, procuramos renunciar às definições prévias de desenho, buscando investigá-lo como experiência, momento que antecede e funda categorias e conceituações.

A fenomenologia, compreendida no movimento iniciado por Edmund Husserl (18591938), pretende o "estudo descritivo de todos os fenômenos que se oferecem à minha experiência de sujeito" (DEPRAZ, 2011, p. 7), ressaltando que toda consciência de algo é, necessariamente, a consciência de alguém sobre algo. Essa reciprocidade entre sujeito consciente e objeto da consciência, chamada de intencionalidade, é a base que sustenta toda forma de conhecimento, na perspectiva fenomenológica. Assim, uma de suas importantes contribuições é a investigação de como uma mesma coisa pode se mostrar de maneiras diferentes a consciências diferentes, assumindo um caráter descritivo e não explicativo dos fenômenos. 
$\mathrm{Na}$ abordagem de Maurice Merleau-Ponty, os diferentes sujeitos, a partir de pontos de vista singulares, partilham um mundo comum que se oferece como horizonte para suas experiências. Para o filósofo, estamos atados ao mundo e à dada situação histórica, sendo preciso afrouxar a trama que nos ata ao mundo, olhá-lo com estranhamento, interrogando a confortável mediação dos conceitos e pressupostos com os quais se constroem ideias sobre o mundo. Ao questionar a ciência e seus modelos de pensamento que fazem do mundo objeto de suas operações, Merleau-Ponty critica o dualismo sujeitoobjeto e propõe o retorno à relação originária do sujeito e do mundo, viabilizado pelo retorno ao mundo percebido, pré-reflexivo, onde se enraízam todas as formas de consciência. Isto não significa renunciar às estruturas reflexivas pelas quais o mundo cultural é representado, mas penetrar no solo que o sustenta para melhor compreendêlo, visto que não há ideia de mundo que não esteja ancorada em experiência do mundo.

Segundo o filósofo, o mundo percebido é o mundo que se oferece aos sentidos. É

berço das significações, sentido de todos os sentidos, e solo de todos os pensamentos, o meio de ultrapassar a alternativa do realismo e do idealismo, do acaso e da razão absoluta, do contrasenso e do senso (MERLEAU-PONTY,1971, p. 433).

Nesse território de fronteiras permeáveis e sentidos entrecruzados - visão, olfato, audição, tato - as coisas sensíveis se manifestam em sua integridade. Esse fenômeno originário ou abertura do mundo são para Merleau-Ponty sinônimos de experiência, através da qual são atualizadas significações fundamentais (PASCAL, 2010, p. 27).

$\mathrm{Na}$ perspectiva merleau-pontyana, a arte exerce essa forma de conhecer em cumplicidade com o aparecer do mundo, como abertura às interrogações, sendo capaz de interromper momentaneamente o pensamento sobre as coisas e apresentá-las à percepção. Esse aspecto do fenômeno artístico também é assinalado por Georges DidiHuberman (2009, p.37), que o verifica na atividade dos artistas:

Pelo menos, deslocando os pontos de vista, revirando os espaços, inventando novas relações, novos contatos, sabem encarnar as questões mais essenciais, o que é bem melhor que acreditar responder a elas.

Conforme Merleau-Ponty, ao reabilitar o mundo percebido, a arte explicita os fios intencionais que atam sujeito e objeto. Em constante atualização, o mundo percebido é revisitado e reaparece em cada investida do artista no mundo, através do seu trabalho, em cada efeito da obra de arte nos sujeitos que a percebem, todos participantes da experiência artística. A experiência artística vai de encontro ao modo como as coisas aparecem, atuando no inacabamento desse mundo, através do qual há sempre 
aparecimentos, e que "não é apenas o conjunto de coisas naturais, é também os quadros, as músicas, os livros" (MERLEAU-PONTY, 2004a, p.65).

Ao tomar o desenho como fenômeno, pretendemos ir ao encontro dessa experiência prévia, para compreendê-la como gênese dos discursos sobre o desenho. Acolhê-lo como parte de um mundo vivido, em detrimento de um mundo refletido e pensado, na medida em que não há uma essência de desenho a ser decifrada fora da existência e da intencionalidade. Relacionados um ao outro pela visualidade, aquele que vê e o visível emprestam um ao outro as chaves de sua abertura, pela reciprocidade do olhar. Observa Valéry (2003, p.125) que

As coisas nos olham. O mundo visível é um excitante perpétuo: tudo desperta ou alimenta o instinto de se apropriar da figura ou do modelado da coisa que o olhar constrói.

O desenho pode ser compreendido, então, como esse modo de construção do olhar, que abrange todos aqueles que enxergam, que respondem à excitação do mundo visível, podendo ser interpretado no solo da vida intersubjetiva, aquela em que todo humano se vê enredado como participante de um mundo percebido comum. Sendo uma experiência criadora ancorada no mundo percebido, desenhar é demonstrar o interesse pelo perceber, enfim, "é ter atenção aos traços do mundo" (CHUí; TIBURI, 2010, p.63). O desenhista eleva ao máximo esta atenção na experiência artística, evidenciando-a no traçado sobre superfícies, procedimento já sedimento na cultura artística e do desenho, que é interrogado e atualizado em cada experiência criadora.

$\mathrm{Na}$ descrição da experiência criadora, Merleau-Ponty chama de Espírito Selvagem o espírito prático, impulsionado pelo agir, determinado a romper a carapaça do aparelhamento do pensado, com intuito de reativar, refundar, interrogar as significações. É aquele a quem não satisfaz a cultura, o estabelecido, mas interessa o indeterminado que sua força criadora pode determinar; o invisível que pode tornar visível. Esta experiência vai à origem da cultura, para instituí-la de novo. Nessa zona, chamada pelo filósofo de Ser Bruto, o artista (e desenhista) se aventura na simultaneidade dos modos de ser do sensível - visão, tato, olfato, audição. O Espírito Selvagem vai à simultaneidade dessas manifestações expor sua modalidade presente. O artista, situado no cerne da experiência criadora, recorre a esse campo relacional no qual uma cor só pode ser em relação à outra, como uma diferenciação entre cores; a forma só pode ser entre formas, a linha entre tantos traçados, o claro entre tantos escuros. O Ser Bruto condensa as modulações que possibilitam o sistema expressivo empregado pelo artista. Através da ação do Espírito Selvagem, "a arte e notadamente a pintura, nutrem-se nesse 
lençol de sentido bruto do qual o ativismo nada quer saber." (MERLEAU-PONTY, 2004b, p.16)

Posto que as manifestações do visível não estão nem na coisa desenhada, nem naquele que desenha, o desenho realiza-se na promiscuidade entre elas e o olho. "Abramos os olhos para experimentar o que não vemos", convoca George Didi-Huberman (1998, p.34), chamando a atenção para aquilo que Merleau-Ponty compreende como ação do Espírito Selvagem no Ser Bruto. Para Didi-Huberman, esse é o trabalho visual experimentar o que não vemos - a que o sujeito é convocado quando está diante da criação, da obra de arte por fazer ou fruir: experimentar a visualidade em suas profundezas invisíveis, naquilo que ultrapassa a evidência da visão, mas a mobiliza e potencializa. Admitindo-se, então, o mistério que aí se encontra, não cabe explicar a visão, mas experimentá-la, pela iniciação.

Com o exercício da experiência, observa-se o movimento em direção ao exterior, ao fora, a abertura ao percebido; e com a iniciação, observa-se o movimento contrário, o vir para dentro, a volta à interioridade ou origem. Logo, percebida, doravante como nosso modo de ser e de existir no mundo, a experiência será aquilo que ela sempre foi: iniciação aos mistérios do mundo. Ao desenhar, o artista traz as coisas ao visível pela e na experiência da criação. Através do desenho, pelo traço, o artista abre uma fenda no percebido, para demonstrar que ele existe.

"Traço. É neste lugar que cabe propor o problema do desenho como chão, como início e como fundamento" (CHUÍ;TIBURI, 2010, p.79). Traço é sinônimo de risco ou linha, que em desenho adquire caráter de demarcação de contorno ou fronteira, delineamento ou corte, intervenção em algo que demarca e marca. Indica percursos, direções, sentidos. É preenchimento e fenda, contato e separação, intervenção no indiferenciado que faz a diferença. O traço é a cicatriz da experiência da visualidade, a marca da cisão do estofo do mundo que revela vidente e visível, um para o outro. É animação no invisível que introduz o desenhista ao mundo percebido.

\section{A arte ao alcance da criança e em Amador Perez}

O interesse pelo desenho se manifestou cedo na carreira do artista. Entre 1966 e 1968, cursou desenho com Aloísio Carvão, no Museu de Arte Moderna do Rio de Janeiro (MAMRJ). A arte brasileira havia vivido a contundência dos movimentos construtivos nos anos de 1950, que tiveram na figura de Aloísio Carvão um de seus principais representantes. $\mathrm{O}$ aprendiz de desenho encontrou no mestre um artista/professor oriundo do rigor da linguagem geométrica, mas consciente da arte como território permanente de 
interrogações e experiências, marcado pela trajetória neoconcreta e aberto a utilização de materiais diversificados, capazes de efeitos sonoros e de movimento, além de cromáticos. A herança geométrica caracterizada pelo rigor, pela consciência da forma e pela atitude construtiva, combinada com o exercício da sensibilidade e reflexão sobre o fazer artístico pode ser notada nos desenhos de Amador Perez.

Em sua educação formal, além de Aloísio Carvão, encontram-se diversas referências significativas, cruciais no desenvolvimento de sua poética artística ${ }^{2}$. Contudo, nosso interesse nesse artigo é enfocar uma simpatia prévia, a instauração de uma congenialidade (PAREYSON, 1997, p.226) ${ }^{3}$, que enraíza esse desenvolvimento em experiências anteriores associadas ao aprendizado informal da arte. Perez (2012), ao lembrar a mãe, ilustra essa experiência precedente que repercute na formação do artista:

Ela fazia brinquedos para gente, que a gente não tinha tanta grana para comprar. Então ela fazia brinquedos. Tinha um sapo que era fantástico, não era bem um sapo, era um polvo, não sei que diabo era aquilo, que a gente zunia aquilo no ar... Ela que tinha costurado, ela que tinha botado a estopa, ela desenhava aquilo tudo e confeccionava. Então, cara, é uma formação assim... estar perto do Aloísio, para mim, foi o máximo, porque eu via tudo isso reunido nele, só que ele era um cara culto.

Se o mundo da cultura, que abrange museus, ateliês, oficinas e cursos, a prática dos artistas com os quais conviveu e as imagens com as quais se confrontou, constitui a formação do artista e manifesta-se em sua poética,

claro está que este dom é merecido pelo exercício, e que não é em poucos meses, nem tão-pouco na solidão, que um pintor entra na posse de sua vida. A questão não está aí: precoce ou tardia, espontânea ou formada no museu, a sua visão, em todo caso, não aprende senão vendo, não aprende senão consigo mesma. (MERLEAU-PONTY, 2004b, p. 25)

Gostaríamos, então, de tratar aqui dessa visualidade, aprendizagem experimentada de tal maneira que é a ela que um artista retorna sempre, quando confrontado com o mundo da cultura e da arte, de onde extrai suas impressões e para onde dirige seus interesses, orientado por uma espécie de sabedoria da visão. Merleau-ponty, ao discorrer sobre o trabalho do pintor, esclarece que sua prática é regida pela visualidade, "porque o mundo, pelo menos uma vez, gravou nele a cifra do visível" (Ibid, p.27). Com o desenhista e

\footnotetext{
${ }^{2}$ Além da importância dos exercícios propostos por Aloísio Carvão, Amador Perez destaca os encontros com Anna Bella Geiger, a sensibilização através das palestras de Fayga Ostrower, as descobertas nas aulas de Hélio Eichbauer, experiências relacionadas aos cursos do MAM-RJ e da Universidade Federal do Rio de Janeiro.

${ }^{3}$ Encontro de gênios, sintonia onde aspectos de um identificam-se com os de outro. Pareyson considera que ocorre congenialidade no processo interpretativo da obra de arte, quando esta sintonia ocorre entre aspectos de quem olha e a forma artística para qual se dirige.
} 
outros artistas da visão, não é diferente. Em algum momento o mundo gravou em Amador Perez essa cifra. Sendo assim, observaremos momentos-chave nos quais ela parece se revelar.

São momentos de abertura à visualidade, sempre recomeçada pela frequentação ao mundo da arte, perseguida voluntariosamente pelo artista visual na sua profissão e vivida como um despertar do olhar, cujo início é incerto. É mais apropriado falar de iniciação, no sentido já esclarecido pela fenomenologia da percepção merleau-pontyana. Momento fundador, anterior e simultâneo à educação formal e profissional, mas que a enseja e orienta. A iniciação de Amador Perez se dá pela introdução da criança ao mundo da arte.

Podemos recorrer a alguns momentos dessa introdução, guiados pelo relato do próprio artista, que destaca os momentos em que assistia ao pai, arquiteto, desenhar para ele e para o irmão.

Minha formação foi em casa, vendo meu pai rabiscar, [...] O cara tinha uma percepção espacial que eu ficava besta! A minha diversão e a do meu irmão, quando éramos pequenos, era ir até o escritorinho, ele tinha uma sala aqui no centro da cidade, ali ao lado do Teatro Municipal - aquele conjunto ali é muito importante para mim, Teatro Municipal, o Museu de Belas Artes, principalmente - a gente estava todo dia ali. [...] Aí ele ficava brincando, olha que maravilha. Ele pegava aqueles cotocos de grafite, americanos, assim bem largos, e ficava rabiscando: 'Amadorzinho - ele nos chamava de Amadorzinho e Luis Antônio, Lula, meu irmão, que é o mais velho - onde você quer ficar?' 'Ah, quero ficar em cima do abajur, quero ficar pendurado no lustre'. (risos) Aí ele desenhava a gente nos interiores, nas perspectivas. [...] Quer dizer, eu fui contaminado pelo ato mágico de ver meu pai desenhando, mas na verdade eu exerci mesmo a função sensível, vamos dizer assim, que a minha mãe projetou sobre mim e sobre meu irmão." (PEREZ, 2012)

Esses desenhos, "atos mágicos", que podiam ser pequenos seres modelados em miolos de pão na hora do café ou os irmãos retratados entre arquiteturas e perspectivas, forneceram ao Amador menino, chaves de acesso à visualidade, que exige criação para trazer do invisível, o visível. As situações lúdicas, despretensiosas e envoltas em afetividade, iniciaram o artista ao olhar atento, ao trabalho visual necessário ao artista. Figuras criadas, nascidas do desenho aos olhos da criança, eram deslocadas pelo pai em cenários desenhados no papel ou pela imaginação do espaço vivido. Recriava-se o próprio mundo e um mundo próprio, um mundo percebido onde relações visuais, espaciais e temporais são reveladas pela experiência e pela iniciação. Assistindo a si mesmo como parte do desenho e à sua própria iniciação, Amador Perez testemunhava o surgimento de um campo de possibilidades expressivas pelo desenho. O futuro artista 
podia ver nos desenhos do pai, uma série de reinvestidas a um mesmo mundo que nunca se apresenta inteiramente e pronto, mas exige criação para vir a ser. Esses momentos se atualizam na poética do artista:

Eu percebo isso tudo como uma volta, uma reinfância, como diz Frederico Morais. Ele se preocupou com isso. Essa coisa do meu pai, que desenhava a gente, sabe, sentado em cima do abajur, pendurado no lustre, em cima do armário, da perspectiva de interiores dele lá, é isso... Eu faço isso até hoje. Eu tiro daqui, boto para lá, troco. Um vastíssimo campo experimental. (PEREZ, 2012).

Nesse contexto de experiências iniciáticas, destaca-se um marco significativo: $A$ arte ao alcance da criança ${ }^{4}$. Esse livro dirigido às crianças apresenta-lhes o mundo da arte, através da articulação entre imagens e texto de modo a mostrá-las como o trabalho executado pelos artistas coloca certos aspectos do mundo "ao alcance dos nossos olhos" (D'AMICO, in: BLAND, 1954), convidando o leitor a desfrutar esse mundo e experimentálo pela execução. Encontram-se reproduzidas obras de épocas, culturas e técnicas diversas, sem a preocupação de apresentá-las em ordem cronológica ou segundo estilos e movimentos históricos. Às reproduções das obras, são intercaladas fotografias que registram aspectos do mundo natural, crianças em momentos de criação artística ou em contato com obras, além de desenhos realizados por crianças. Todas essas imagens, somadas aos textos curtos, claros e provocativos, estão articuladas de modo a cumprir o propósito de ressaltar o poder revelador da visualidade, quando acionada pela experiência artística. Nas palavras de Amador Perez (2012),

É um livro maravilhoso como referências, fantástico mesmo. Porque é uma coleção americana, traduzida para o português. E ali eu tenho de um tudo. Desde um hipopótamo egípcio, até um quadro do Rothko. E eu com oito aninhos, sete aninhos de idade, eu adorava aquilo tudo. [...] Cara, o texto desse livro é uma beleza! [...] Aí eu aprendi, a minha formação está aí. [...] Você tem um Henry Moore do lado de um desenho do Ingres. É uma leitura espetacular desse autor do livro ou desses autores. [...] É uma curadoria genial, vamos combinar. [...] Você tem uma seda chinesa se relacionando com um Jasper Johns.

Podemos observar que não é uma preocupação da publicação ensinar ou explicar a arte à criança, mas descrever a experiência artística a partir de exemplos diversos, que vão da obra de arte consagrada pela história à vivência da própria criança. Desse modo, consegue abordar o fenômeno artístico em suas diversas e ricas perspectivas: motivações dos artistas, relações entre forma e conteúdo, diversidade e possibilidades expressivas dos materiais. Problematiza a visualidade e a arte como experiências

\footnotetext{
${ }^{4}$ A tradução desse volume da coleção O mundo da criança é de Dinah de Barros Menezes e Iva Waisberg Bonow. Texto de apresentação de Victor D'Amico, Diretor Educacional do Museu de Arte Moderna de Nova Iorque.
} 
aparentadas e coniventes na tarefa de revelação do mundo percebido. Provoca o olhar da criança, que se vê estimulada a ingressar nas situações propostas, portando-se como vidente capaz de operar o visível pela experiência criadora. No livro, essa experiência é apresentada como inerente a qualquer sociedade humana, que na conciliação de aspectos particulares e universais pode executá-la, compartilhá-la e dela se enriquecer.

Cabe salientar, através de alguns exemplos, o compromisso do livro em valorizar a experiência e a variedade de modos de execução das obras, aspecto que afetou Amador Perez, como artista. Isso se mostra, principalmente, pela constante presença da figura de crianças no livro, tanto quanto das obras de arte. Em todas as imagens, as crianças estão experimentando situações artísticas, nas quais seus corpos e visões estão concentrados e envolvidos na atividade (Figura 01). Notam-se, nesse conjunto de imagens, flagrantes da presença condicional do corpo, guiando a experiência e sendo por ela guiado, com a visão entregue e participativa, acompanhando a evolução do processo. Essa participação corporal operante e atual, imprescindível à arte visual, também é ressaltada no livro com exemplos extraídos do próprio mundo da arte, nos quais artistas representam o momento da realização artística. Recorrendo ao discurso visual presente nas imagens, a autora enfatiza o quanto essa realização está "ao alcance da criança" e integra o desenvolvimento geral do homem e dos artistas, servindo como referência sempre atualizada de co-pertencimento e cooperação em relação ao mundo percebido. 

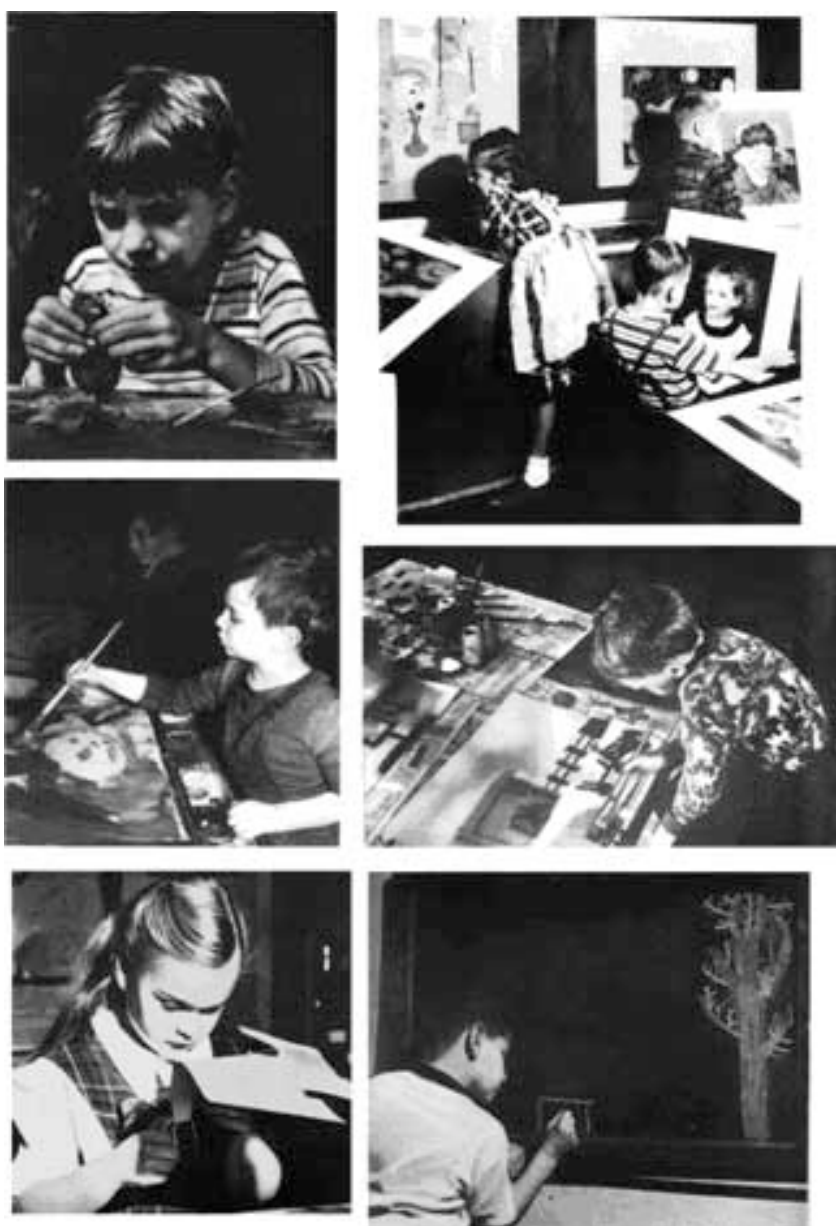

Figura 01. Seleção de fotografias extraídas do livro $A$ arte ao alcance da criança.

Em outro momento do livro, são colocados lado a lado, em página dupla, dois retratos de crianças que exibem desenhos de figuras humanas (Figura 02). Aparentam orgulho de sua produção e, ao mesmo tempo em que confrontam o espectador, olhando-os frontalmente, posicionam seus desenhos também a fitá-los. A autoria dos desenhos é exaltada pelas mãos que os seguram com proximidade. Mas o gesto predominante é o de mostrar, de dar a ver, sublinhando que o mundo percebido, manuseado pelo artista, é todo mostração. 


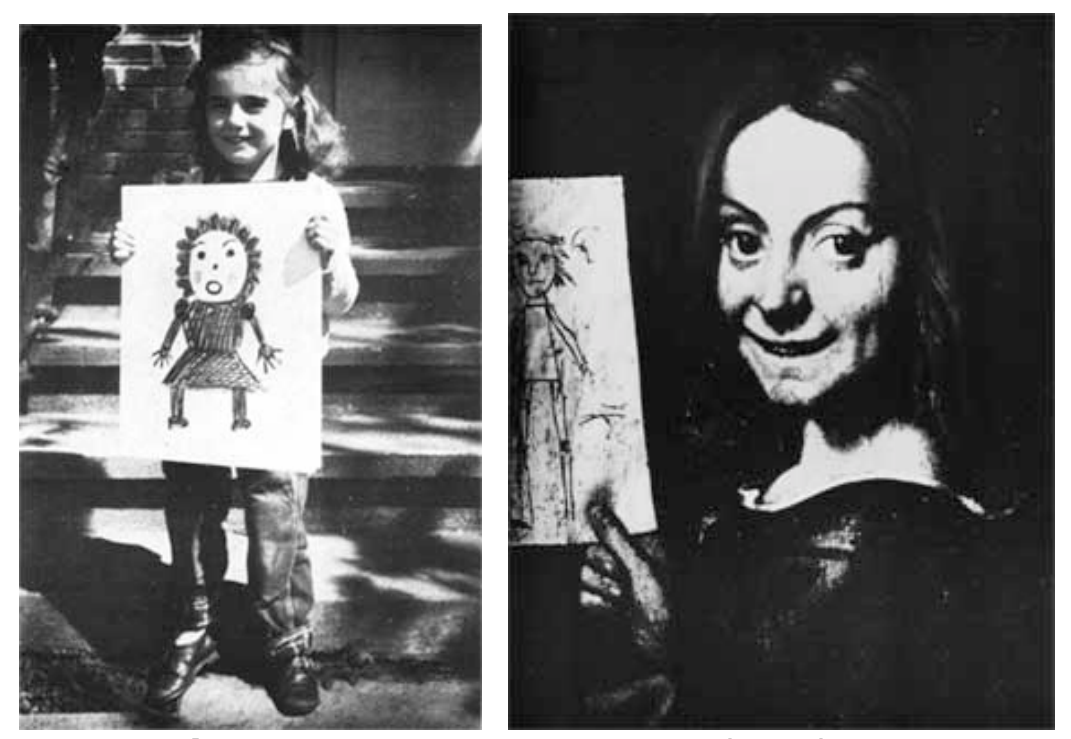

Figura 02. Crianças com seus desenhos.

Imagens extraídas do livro $A$ arte ao alcance da criança.

Essas questões parecem convergir em Cláudio ao Cavalete (Figura 03). Diante dessa imagem, o leitor assiste a um triplo acontecimento: a execução de uma obra por Cláudio, filho artista, que assiste a si mesmo ao executá-la frente ao cavalete; o testemunho e registro desse acontecimento pelo pai, traduzindo-o em sua própria experiência artística ao retratar o filho; e, ainda, a possível identificação do leitor com a imagem, que se vê estimulado a se aventurar na experiência artística, conforme Cláudio.

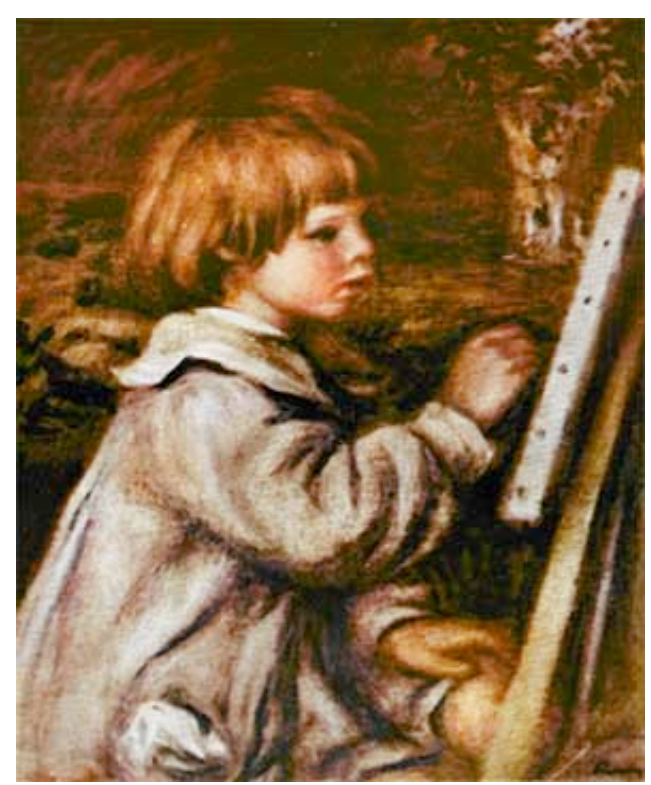

Figura 03. Pierre Auguste Renoir, Cláudio ao cavalete. Imagem extraída do livro $A$ arte ao alcance da criança.

A partir desses exemplos observados no livro, podemos notar que a exaltação da visualidade e da arte como sua consagração perpassa toda leitura de $A$ arte ao alcance da criança. A leitura dos textos e das imagens é pontuada por questionamentos sobre a pluralidade de modos de ver denunciada pela arte, como na sequência de imagens a 
partir da questão "o que você vê nesta estampa?", lançada junto à fotografia de um cavalo (Figura 04).

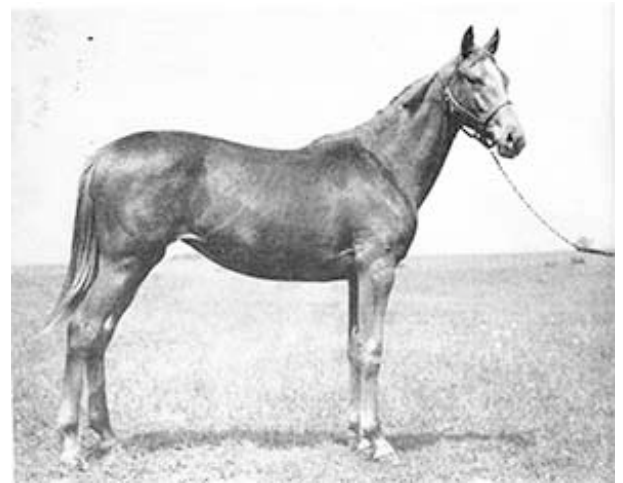

Figura 04. Imagem extraída do livro $A$ arte ao alcance da criança.

Depois de apresentar algumas hipóteses (cavalo "vigoroso", "grande" e "forte", a posição "elegante", o pelo "lisinho e lustroso"), a autora confronta o leitor com uma sequência (Figura 05) de "gravuras de cavalos feitos pelos mais diversos artistas" (BLAND, 1954, p.63).

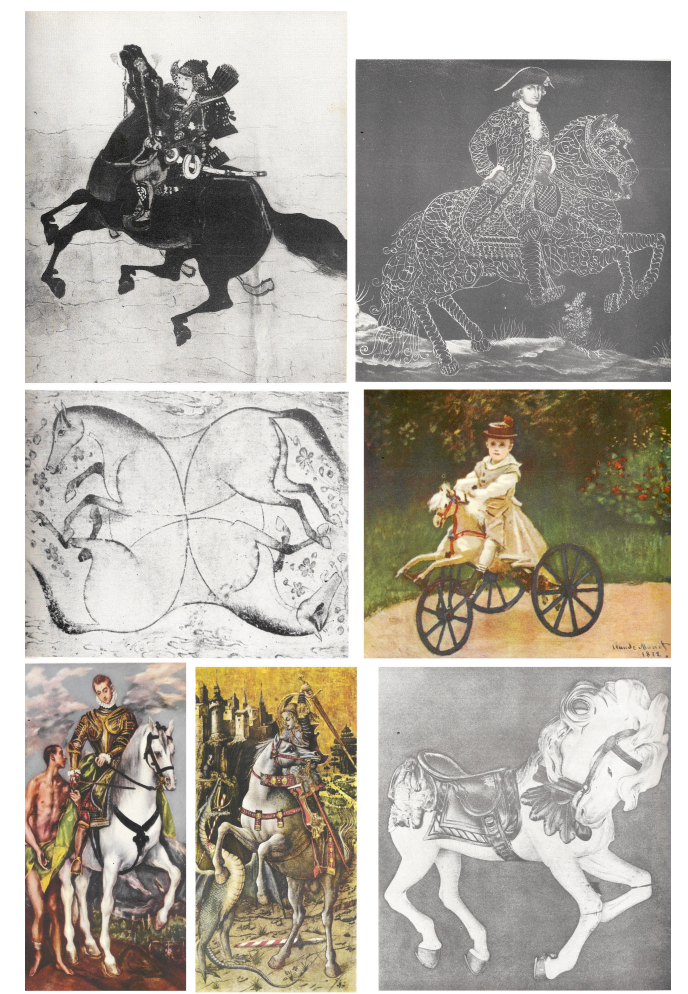

Figura 05. Cavalos nas visões de diversos artistas. Imagens extraídas do livro $A$ arte ao alcance da criança.

Essas reminiscências envoltas em afetividades parecem constituir momentos fundadores, presentes e renovados na obra do artista maduro e profissional. Em grande parte de seus 
trabalhos elas ecoam, estabelecendo, por exemplo, diálogos com a fotografia do cavalo disponível no livro (Figura 06 e Figura 07) ${ }^{5}$.

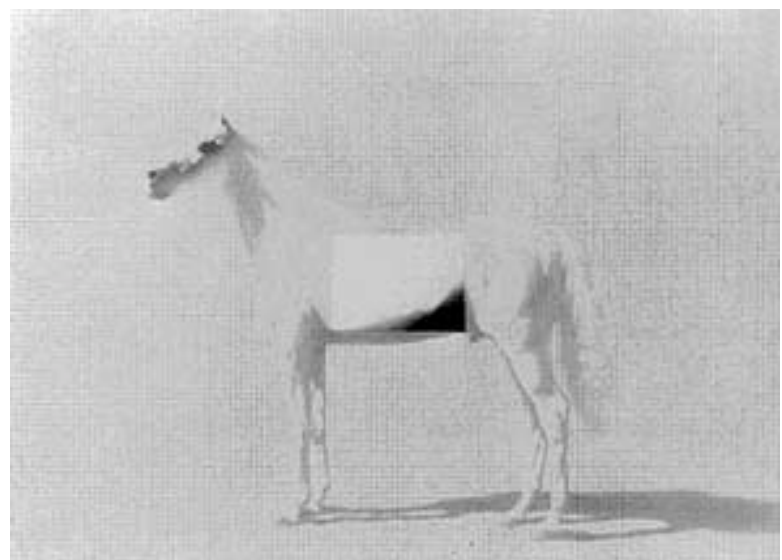

Figura 06. Amador Perez. Sem título. Grafite, 11 x 15cm,1982-83.

Disponível em http://www.amadorperez.com/porfram.htm

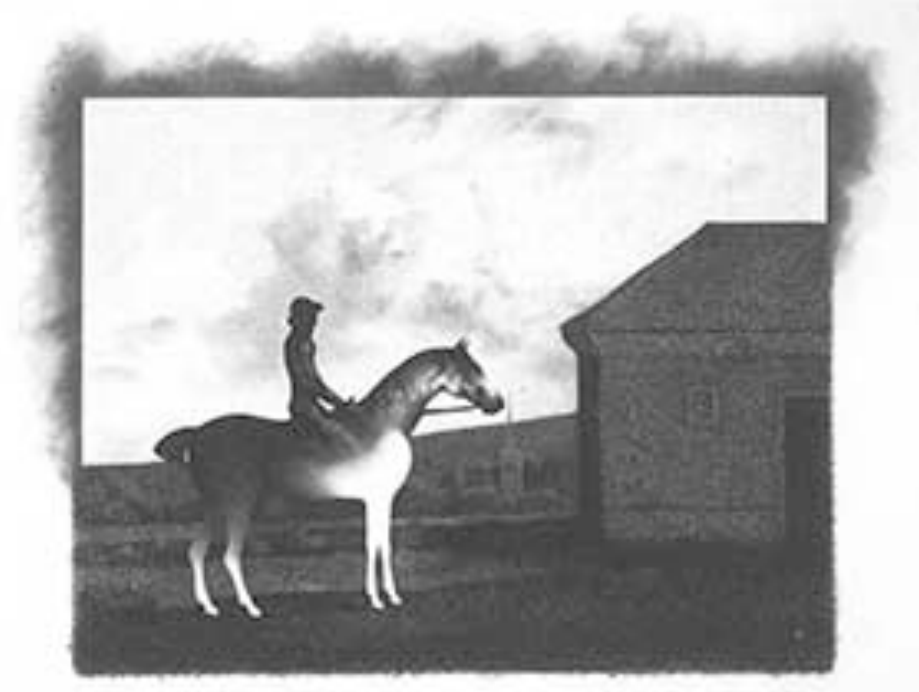

Figura 07. Amador Perez. Desenho da série baseada em obras de Stubbs. Grafite, 12,5 x 9,5cm, 1985-87. Foto: Coleção do Artista, 1999.

A interação entre Amador Perez e esse livro foi intensa. Executou, quando criança, inúmeros desenhos a partir de suas estampas, munido do primeiro cavalete e, principalmente, da ferramenta mais acessível de que dispunha: o lápis. É ao cavalete que Amador Perez se encontrará daí em diante, motivado pela repetição dos momentos iniciáticos vividos pelo intermédio do pai e das obras com as quais se confrontou, principalmente as circulantes nos meios impressos. Ao copiar as obras que via reproduzidas nas ilustrações, Amador Perez tentava copiar, principalmente, o modo de

\footnotetext{
${ }^{5}$ A relação percebida pela autora foi confirmada pelo artista em depoimento prestado a mesma.
} 
executar de cada artista, decifrando seus sistemas de equivalências para trazer o mundo à visualidade, descobrindo o mundo percebido cifrado pela experiência artística. Alimentado por sentimentos positivos e afetuosos, o espírito do artista foi sendo forjado nesses eventos, processo continuado e realimentado durante os cursos realizados na juventude. O significado desses exercícios é destacado por Wilson e Wilson (2005, p. 60$61)^{6}$, baseados em pesquisas que desenvolveram sobre o papel da imitação no processo de aprendizagem do desenho:

É necessário compreender que o aprendizado mais importante de arte está intimamente ligado ao processo de perda da primeira inocência por meio do ganho da experiência temporal. De fato, o processo de perda da ingenuidade em arte envolve a aquisição de convenções artísticas - processo limitativo este que por muito tempo permaneceu escondido. Ele necessita de ser trazido à luz. Este processo de aquisição de convenções, que se torna mais predominante e óbvio em crianças com oito ou nove em diante, é, cremos, mais importante do que qualquer outro no desenvolvimento artístico, porque é o processo que permanece operacional durante toda vida. [...] observamos que as crianças mais bem-dotadas e produtivas em arte desenham primariamente a partir de imagens derivadas das medias populares e de ilustrações [...] Crianças que foram observadas trabalhando a partir dessas fontes estavam bastante avançadas em sua habilidade de construir ideias visuais e na representação de coisas como esboço, perspectiva, ação em desenhos.

Os autores ressaltam a semelhança entre esse processo e a aquisição da linguagem verbal pelas crianças, que aprendem a falar a partir do convívio com modelos de fala a que estão expostas, na vivência da língua e descoberta de seus modos de execução. No desenho, a diferença está no emprego de signos configuracionais, diferentes dos signos verbais. Guardadas as especificidades de suas naturezas, a imitação está presente em ambas as aprendizagens.

A criança aprende a formar seus próprios signos configuracionais principalmente por meio da observação do comportamento-defazer-signos-configuracionais de outras pessoas, por observar inicialmente que outras pessoas fazem desenhos, verificando então, a maneira pelo qual são feitos, as razões pelas quais são feitos, as situações nas quais são feitos, a variedade de signos configuracionais feitos e as diversas formas que tais signos tomam em nossa cultura. (Ibid, 2005, p. 63).

Amador Perez encontrou nas experiências relatadas de sua infância a oportunidade de assistir ao "comportamento-de-fazer-signos-configuracionais" de outras pessoas, tanto através dos exemplos paterno e materno, quanto das reproduções disponíveis para serem copiadas. Afinal, como dizem os pesquisadores, "não será por meio de nenhum

\footnotetext{
${ }^{6}$ Publicado originalmente na revista $A r^{\prime} t e$, ano I, n. 1, 1982.
} 
tipo de exame das nuvens que a pessoa aprenderá a desenhá-las". Amador Perez (2012) destaca o valor desse aprendizado:

Cara, isso tudo vale diamante, para mim. O que eu estou fazendo até hoje? Quando eu era garotinho eu copiava essas figuras. Tal a vontade que eu tinha de entrar nelas e de ser penetrado por elas. Então, eu fui penetrado por essas imagens todas. Eu, Amador, não estou dizendo que isso é uma regra geral para todo artista, eu faço e refaço essas imagens, de todas as formas possíveis, de acordo com interesses meus. [...] Eu recorro à minha rose bud. [...] Eu viajava nessas imagens, entendeu? [...] Eu tenho de oito, nove, dez, onze, doze anos de idade, reproduções que eu fazia do Rafael, do Da Vinci. Sempre, essencialmente, o tempo todo eu estava copiando. Eu queria ser eles. Eu queria entrar na máquina do tempo e vivenciar o processo histórico. Eu queria entrar no corpo dessa gente. Eu queria ser a alma deles entrando nesse corpo.

Podemos compreender o laço afetivo que Amador Perez estabelece com o desenho, a partir desses relatos. E o virtuosismo de sua poética, que poderia ser interpretado, ingenuamente, como exaltação da semelhança com o real, representação fidedigna da aparência das coisas, na verdade, interroga a aparência das imagens.
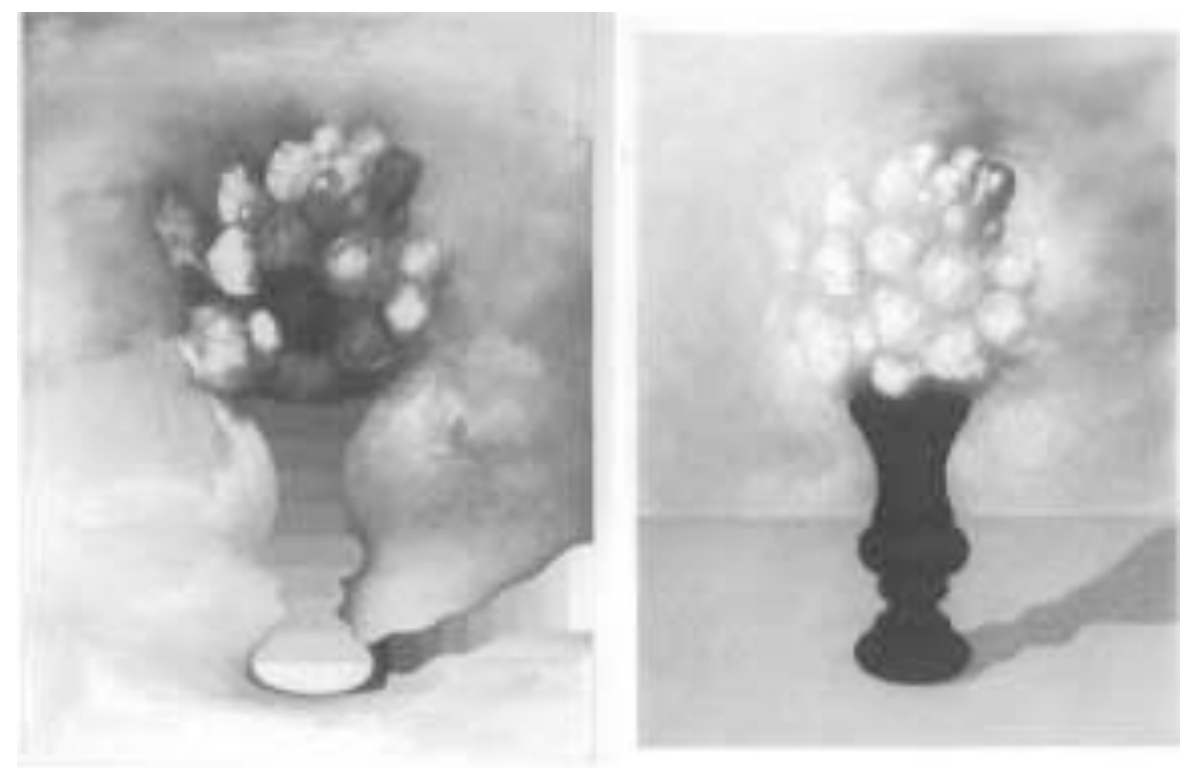

Figura 08. Amador Perez. Sem título. Desenhos a partir de Vasetto com rose, de Giogio Morandi. Grafite, 21 x 16cm, 1992-94. Foto: Coleção do Artista, 1999.

O uso frequente do exercício da cópia, espontâneo e lúdico, com fontes de imagens escolhidas pelo próprio artista-criança, converteu-se em ambiente propício para a formação de um vasto e rico repertório de soluções plásticas por meio do grafite, material que nem sempre coincidia com aqueles empregados pelos autores das obras de referência. É o modo com que elas podem aparecer, pintadas, gravadas, fotografadas, impressas, enfim, que Amador Perez espera exaltar quando opera com maestria as 
convenções artísticas que sobrevivem nas reproduções (Figura 08). A transitividade da imagem em diversas encarnações, da gravura ao desenho, da pintura ao desenho, da fotografia ao desenho, também importa. A excelência técnica está a serviço, então, da visibilidade da imagem e não do real, sendo os sistemas de equivalências ou signos configuracionais inventados e adotados como resposta a um mundo percebido, enquanto revelado pela experiência criadora. Amador Perez tira partido disso ora para esclarecer, ora confundir o espectador, em relação aos efeitos dos materiais. $O$ desenho às vezes se assemelha à gravura, às vezes se assemelha à fotografia, dependendo de como a natureza do grafite e do papel são provocados pelo artista. Ao redesenhar imagens, Amador explora o virtuosismo para imitar e questionar os efeitos da materialização da imagem em nossa percepção.

Os primeiros trabalhos profissionais de Amador Perez datam de 1973 a 1975 e, como uma perseverança das experiências de infância, aprofundadas e maturadas, são desenhos a grafite realizados a partir de reproduções disponíveis em mídias impressas diversas. Nos primeiros trabalhos, a apropriação se limitava à transposição das imagens para a linguagem do desenho, sem que o artista alterasse os elementos ou a composição originais, mas ressaltasse o realismo e conferisse à banalidade dessas imagens, reproduzidas em massa, o tempo e a singularidade do fazer artístico (MORAIS, In: PEREZ,1999).

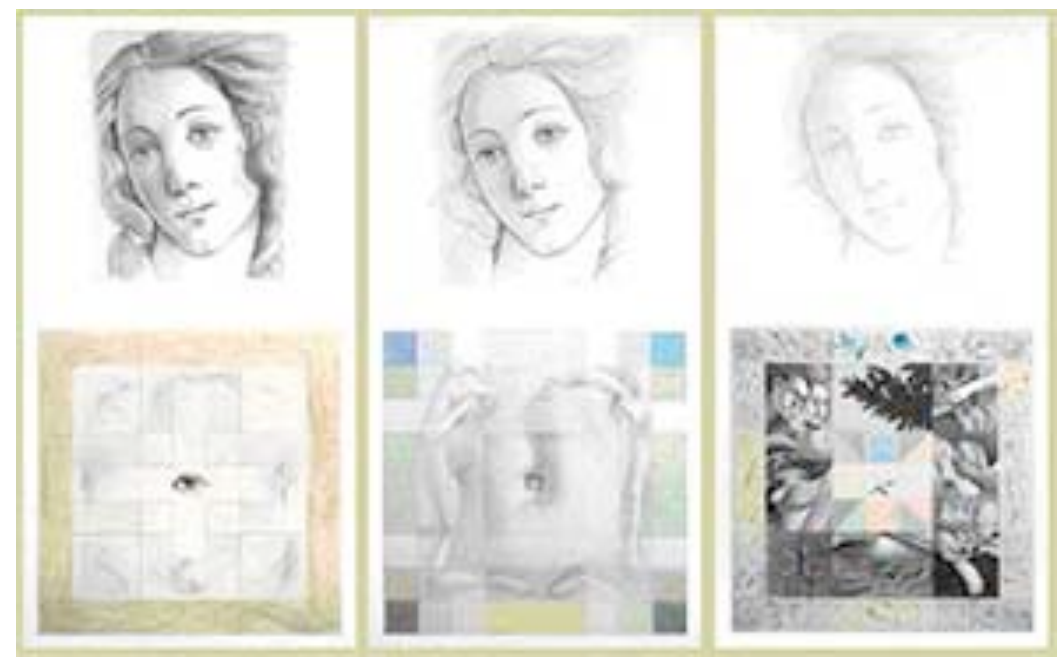

Figura 09. Amador Perez. Sem título. Grafite e lápis de cor, baseado em Nascimento de Vênus, de Botticelli, $8 \times 16 \mathrm{~cm}, 1984$. Disponível em http://www.amadorperez.com/por_fram.htm

Nos trabalhos subsequentes, a partir da década de 1980, aos fragmentos apropriados o artista passou a adicionar seu próprio repertório pessoal, coreografando-os em composições inventadas. Os fragmentos são figuras humanas, corpos, animais, objetos e cenários que impulsionam a poética do artista a recontextualizá-los num novo quadro 
visual e significativo. Também são desta época os primeiros trabalhos com referência às imagens da história da arte, como a série Musas (1983-1985), dedicada a recolher, reinterpretar e transmutar em desenho figuras femininas de artistas como Botticelli, Vermeer, Goya e Velázquez (Figura 09). A história da arte tornou-se, então, para a poética de Amador Perez, um manancial de signos que o artista decompõem e recompõem com o desenho que, desde os anos de 1990, passou a dividir lugar com as gravuras e meios de reprodução digital.

Rafael Cardoso (2003) se refere ao processo criativo de Amador como alquimia ou transmutação. Mutação de substância em outra, de outro valor, que adquire novo sentido. O artista precisa inventar equivalentes visuais ou configuracionais para a visibilidade que não se constrói fora da aderência do ser ao mundo percebido, atados pela mesma substância. Vale lembrar que o mundo percebido também abarca o dos objetos culturais, que sob a operosidade do Espírito Selvagem, regressa ao solo bruto do sensível, exigindo novas significações.

O estudo da poética de Amador Perez deve atentar, então, para o repertório de imagens das quais se apropria e os meios de que faz uso para redesenhá-las, cuja dimensão material é constituída de qualidades ligadas à substância, forma e intensidade, ingredientes de sua alquimia, que se diferencia pela especificidade do desenho a grafite (Figura 10).
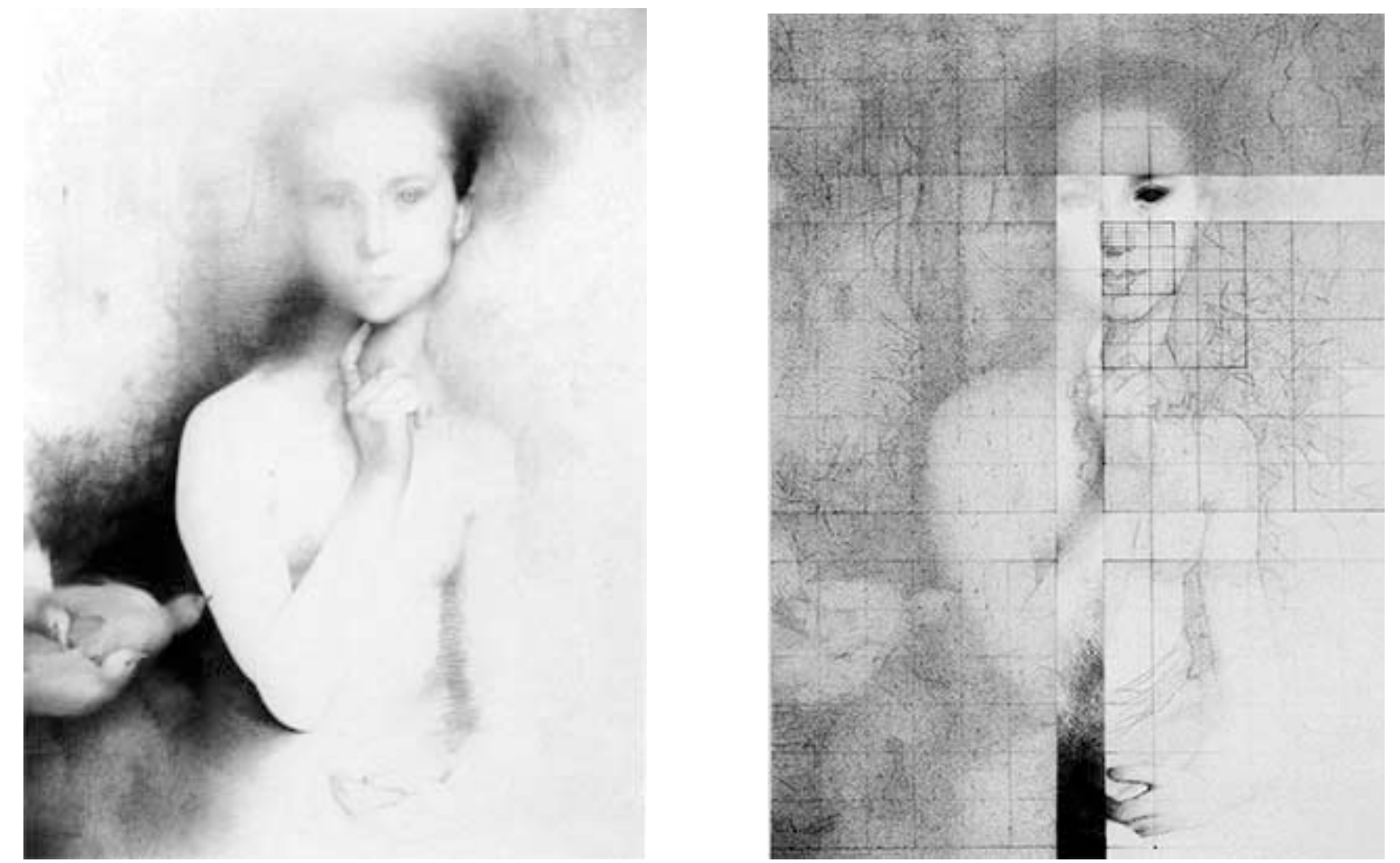

Figura 10. Amador Perez. Sem título. Parte da coleção de 63 desenhos realizada a partir de Gioventù, de Eliseu Visconti.

Grafite, 18 x 13cm, 1996-98. Foto: Coleção do Artista, 1999. 
Para Herkenhoff (1994), "Há um câmbio de corporeidade. A temperatura e carnalidade da pintura transferem-se para o mundo de luzes e sombras e mineralidade do grafite". Trata-se de uma nova realidade da imagem, experimentada tanto pelo artista que a executa pelo fazer quanto pelo espectador que a executa pela interpretação.

Amador Perez necessita observar a imagem de referência, proceder sua inquisição, sendo capaz de traduzir, através de outro recurso material e com fidelidade suas qualidades visuais para, uma vez estabelecida tamanha intimidade com a ordem dada, reinventá-la. Seus desenhos penetram as camadas da imagem apropriada, revelando meandros, intencionalidades, possibilidades, recusas. Restringe o meio ao mínimo, pigmento preto sobre papel, assim extraindo da imagem o máximo, sua complexidade. Com o grafite, o artista tem acesso à materialidade da imagem como teria um cirurgião com seu bisturi:

Eu afino, afino, afino, para que o grafite funcione como um bisturi. Uma tentativa que eu já sei que é impossível, de entender a imagem, compreender a relação que eu tenho com essa imagem em todas as instâncias. Começando na instância afetiva, chegando à instância histórica da imagem. (PEREZ, 2012)

Perez abre a imagem, indo à sua interioridade e mesmo ao seu avesso, para transformála não só a partir de si mesma e das repercussões em seu imaginário, mas das possibilidades expressivas inerentes ao material que selecionou para sua empreitada.

O desenhista atua diferentemente do pintor, que opera na massa de tinta, preenche o suporte, besunta-o com matéria pictórica que tende a se espalhar sobre ele, cobrindo-o. No desenho, o traçado ativa o suporte, aciona a materialidade do papel, que responde às interferências do grafite, estabelecendo com ele mútua afetação. A pressão do traço associado ao grau de dureza do grafite empurra as partículas de carbono nas tramas do papel.

$\mathrm{O}$ atrito. Me interessa isso. Me interessa fazer a imagem penetrar na matéria do papel, ela está gravada ali. [...]Essa coisa de roçar o grafite é uma coisa da minha natureza. O que eu posso te responder objetivamente, é isso. Eu gosto da coisa incisiva, eu sou incisivo, eu sou agudo.[...] Os graus de dureza do grafite me interessam muito. Os mais macios me incomodam, eles já chegam à tinta, eles já chegam perto do pigmento da pintura. Mas eu lido com isso, viu? Aqui tem uns seis grafites." (PEREZ, Amador. Depoimento. Rio de Janeiro, 06 nov. 2012)

E se a pressão é leve, limitando-se a atritar a superfície rugosa, a impressão é de polimento da superfície, como se lustrada, encerada (MAYER, 1999, p.4). Diferentemente de um suporte a ser pintado, cuja resistência à natureza líquida ou pastosa das tintas se impõe, obrigando-as a se acomodar na superfície, o suporte a ser desenhado absorve a 
imagem recortada pelo grafite tanto quanto este se vale de sua presença. A resistência e gramatura do papel são tão significativas quanto a força da ponta de grafite que o fricciona. São duas forças em tensão, atritando-se, afirmando-se em sua alteridade. Cobrir ou descobrir o suporte, preservar ou macular o branco ao desenhar poderia ser comparável a entalhar a pedra, imprimindo-lhe a forma desejada. O papel responde ao grafite assim como a pedra responde ao cinzel, não sendo possível dissimular o fato de que, em ambos os casos, o tom da resposta consubstancia a imagem. Se a pintura é qualificada principalmente por encobrir o suporte, por realizar-se sobre ele, o desenho se realiza com ele. Desse modo, é compreensível a afirmação de Amador Perez de que não há realidade que não seja tridimensional. A bidimensionalidade tão afirmada do desenho é ilusória (PEREZ, 2012). Esse aprendizado inicia-se no exercício do olhar e pela experiência artística. Em Amador Perez, a iniciação vivida na infância se revigora em cada redesenho.

\section{Redesenhos: imagens revisitadas, experiência atualizada}

Amador Perez insiste em revolver a história da arte e recolher, dentre as imagens disponíveis, aquelas que lhe servem de investigação e reinvenção. Nesse artigo, procuramos destacar alguns aspectos dessa poética regida pela revisitação às imagens, que parece ecoar da iniciação à arte, vivida na infância pelo artista. Cada redesenho de Amador Perez é uma reinvestida a esse momento fundador e à construção da significação da imagem, cujo sentido nunca está dado, mas necessita ser acessado pela experiência. Como bem observou Conduru (2005), não interessa a Amador "tanto a representação do mundo, mas, sobretudo o mundo da representação".

Merleau-Ponty, como visto, assinala a indeterminação sob a qual se fundam as determinações, o solo bruto onde a dinâmica das diferenciações é fonte das significações, das representações. Cada vez que um artista o revolve pela experiência artística, uma realidade particular e singular emerge, calcada na atualidade e unidade do corpo com relação ao mundo percebido.

Baralhando os elementos formais pré-existentes nas imagens e suas relações e, com eles, seus conteúdos expressivos e significativos, Amador Perez disseca e desfia a rede de significados tecida na imagem de referência, para fiá-la novamente, revelando vias e desvios da criação e inventando outros. No redesenho, experimenta a ressignificação. Através de reenquadramentos, cortes, rebatimentos, apagamentos, adições, deslocamentos, fraturas, e outros procedimentos possíveis, o artista convida e espectador a ouvir a atuação do Espírito Selvagem sobre a imagem, conduzindo-o nos labirintos da sua criação, mas também inaugura em cada desenho, uma nova obra, 
convidando-o a outros percursos possíveis. Sabendo que a significação não se esgota na imagem e é reinaugurada sempre que acionada pela experiência artística, Amador Perez insiste em reviver a experiência também pelo seu avesso, que é iniciação. Iniciação aos segredos do mundo percebido que o mundo da arte cultiva e ele persegue através da experiência criadora.

Pelos redesenhos, Amador Perez mantém conservado e atualizado acontecimentos fundamentais que lhe marcaram a cifra do visível, como é o caso do encontro com livro $A$ arte ao alcance da criança. Eliseu Visconti, autor de Gioventù, cuja imagem é sempre revisitada por Amador Perez, declarou que "o desenho deve preceder o próprio alfabeto. Ele é a porta por onde a criança tem a revelação do mundo" (Apud CAVALCANTI, 2008, p.19). Uma vez aberta esta porta, Amador Perez continuou experimentando a travessia para frequentá-lo.

\section{Referências}

ALMENDRA, Ludmila Vargas. Experiência do desenho: um estudo sobre poéticas desenhantes e Amador Perez. Rio de Janeiro, 2013. Tese (Doutorado em História e Critica de Arte). Programa de Pós-graduação em Artes Visuais da Universidade Federal do Rio de Janeiro, Rio de Janeiro, 2013.

AMADOR Perez. Artista Plástico. Disponível em: < http://www.amadorperez.com>. Acesso em 2011-2013.

BLAND, Jane Cooper. O mundo da criança: a arte ao alcance da criança. Rio de Janeiro: Editora Delta, 1954, v.10.

CARDOSO, Rafael. Alquimia da imagem. In: PEREZ. Amador. A arte da impressão (catálogo). Rio de Janeiro: UERJ, 2003.

CAVALCANTI, Ana Maria Tavares. Sessenta desenhos de Visconti. In: ELUF, Lygia (org.). Eliseu Visconti. Campinas, SP: Editora Unicamp, Imprensa Oficial do Estado de São Paulo, 2008.

CHUÍ, Fernando. TIBURI, Marcia. Diálogo/Desenho. São Paulo: Editora Senac São Paulo, 2010.

CONDURU, Roberto. Texto para a exposição Impressões da Arte, 2005. Disponível em: <http://www.amadorperez.com>. Acesso em 17 dez. 2011.

DEPRAZ, Natalie. Compreender Husserl. Petrópolis, RJ: Vozes, 2011.

DERDYK, Edith. Disegno. Desenho. Desígnio. SP: Senac, 2007.

DIDI-HUBERMAN, Georges. O que vemos, o que nos olha. São Paulo: Editora 34, 1998.

2009.

. Ser crânio: lugar, contato, pensamento, escultura. Belo Horizonte: C/ Arte, 
HERKENHOFF, Paulo. Preto no branco e/ou, 1994 (Texto para a exposição). Disponível em: <http://www.amadorperez.com>. Acesso em 17 dezembro 2011.

MAYER, Ralph. Manual do artista. São Paulo: Martins Fontes, 1999.

MERLEAU-PONTY, Maurice. Fenomenologia da percepção. Rio de Janeiro: Freitas Bastos, 1971.

. Conversas-1948. São Paulo: Martins Fontes, 2004a.

O olho e o espírito. Lisboa: Vega, 2004b.

PAREYSON, Luigi. Os problemas da estética. São Paulo: Martins Fontes, 1997.

PASCAL, Dupont. Vocabulário de Merleau-Ponty. São Paulo: Martins Fontes, 2010.

PEREZ, AMADOR. Coleção do Artista (Artist's Collection). Rio de Janeiro: Editora Fraiha, 1999 (Textos de Fernando Cocchiarale e de Frederico Morais).

Entrevista concedida a Ludmila Almendra. Rio de Janeiro, 11 out. 2012.

VALÉRY, Paul. Degas Dança Desenho. São Paulo: Cosac Naify, 2003.

WILSON, Brent; WILSON, Marjorie. Uma visão iconoclasta das fontes de imagem nos desenhos de crianças. In: BARBOSA, Ana Mãe Tavares (Org.). Arte-educação: Leitura no subsolo. São Paulo: Cortez, 2005.

i Centro Federal de Educação Tecnológica Celso Suckow da Fonseca - CEFET/RJ.

E.mail: ludric@yahoo.com.br

Recebido em 30/05/2014

Aprovado em 15/12/2014 